Received: 2021/10/26, Revised: 2021/11/27, Accepted: 2021/12/01, Published: 2021/12/31 ๑2021 Magni Mohr et al.; Licence Physical Activity and Nutrition. This is an open access article distributed under the terms of the creative commons attribution license (https:ll creativecommons.org/licenses/by-nc/2.0/), which permits unrestricted use, distribution, and reproduction in any medium, provided the orginal work is properly cited.

${ }^{*}$ Corresponding author : Magni Mohr

Centre of Health Science, Faculty of Health Sciences, University of the Faroe Islands, Jónas Broncksgøta 25, $3^{\text {rd }}$ floor, Tórshavn, Faroe Islands

Tel: +298292270

E-mail: magnim@setur.fo

@2021 The Korean Society for Exercise Nutrition

[Purpose] The purpose of this study was to (i) assess hydration levels in elite male football players during a national team training camp before and during qualifying matches, (ii) evaluate the effect of coaching strategies for hydration based on feedback from hydration monitoring, and (iii) assess possible relationships between hydration status and training load or wellness markers.

[Methods] Thirty-one male players (age $27 \pm 4$ yrs; height $185 \pm 6 \mathrm{~cm}$; weight $82.9 \pm 6.7 \mathrm{~kg}$; body fat $10.4+2.3 \%$ ) representing a national team from the Union of European Football Associations (UEFA) participated. The players were studied during three different national team training camps related to the UEFA Nations League toumament. Urine specific gravity $\left(\mathrm{U}_{\mathrm{SG}}\right)$ was measured to assess hydration status. During all camps, the players were actively coached on improving strategies for hydration and given individual feedback on their test results. The training load was measured using GPS technology, and wellness questionnaires were completed.

[Results] $U_{\mathrm{SG}}$ decreased progressively and significantly $(p<0.005)$ during camp 1 and hydration status improved over the three camps, with fewer dehydrated and more well-hydrated players identified during the last part of camp 3. Significantly $(p<0.05)$ higher $U_{S G}$ values were observed 2 days prior to a match (MD2) than on match day (MD); consequently, $52 \%$ of the players were dehydrated on MD-2 and only $6 \%$ on MD. No correlations were observed between hydration status and training load or wellness markers.

[Conclusion] Dehydration is a challenge in elite male football, but continuous monitoring of hydration status and coaching on hydration strategies can lead to major improvements and reduce the degree of dehydration.

[Keywords] dehydration, nutrition, soccer, wellness, environment, knowledge, performance

\section{Improving hydration in elite male footballers during a national team training camp - an observational case study}

\author{
Magni Mohr 1,2,3* / Eli Leifsson Nólsøe ${ }^{2,3}$ / Peter Krustrup ${ }^{1}$ / \\ Ioannis G. Fatouros ${ }^{4}$ / Athanasios Z. Jamurtas ${ }^{4}$ \\ 1. SDU Sport and Health Sciences Cluster (SHSC), University of Southern Denmark, Odense, Denmark \\ 2. Centre of Health Science, University of the Faroe Islands, Tórshavn, Faroe Islands \\ 3. FSF Sport Science Unit, Faroese Football Association, Tórshavn, Faroe Islands \\ 4. Department of Physical Education and Sport Sciences, University of Thessaly, Trikala, Greece
}

\section{INTRODUCTION}

Football is the most popular sport in the world, with approximately 250 million active players worldwide. Football is a complex team sport that challenges a wide range of physiological and mental abilities that cover the entire performance spectrum ${ }^{1}$.

An appropriate approach to nutrition can result in good health and performance among football players. In-game performance and recovery between matches can be affected by the type, quantity, and timing of food, fluids, and supplements taken by players ${ }^{2}$. Training regimes have become more demanding, and congested match schedules can affect important parameters of performance, including hydration status.

A football player can lose $0.5-3.0 \mathrm{~L} /$ hour of body fluids during training and matches, depending on the intensity of exercise and environmental conditions $s^{3-6}$. There are several methods for assessing euhydration, for instance, a urine osmolality of $<700 \mathrm{mOsmol} / \mathrm{kg}$ or urine specific gravity $\left(\mathrm{U}_{\mathrm{SG}}\right)$ of $<1.020$ suggests euhydration. On the other hand, hypohydration can have a detrimental impact on exercise performance; it has been proposed that cardiovascular strain (due to decreased cardiac output and higher heart rate $)^{7,8}$, impaired cognitive function ${ }^{9}$, increased ratings of perceived exertion ${ }^{10}$, and diminished physical function ${ }^{10}$ and technical skills ${ }^{11}$ are factors contributing to the reduced performance level.

Players should aim to start their training or match fully hydrated and maintain an appropriate hydration status to support optimal performance during the game ${ }^{12}$. Even though it is important for a player to start training or playing in a well-hydrated state, many players start their training sessions and games hypohydrated ${ }^{11,13-15}$. Recent systematic reviews have indicated that pre-exercise hypohydration in football players ranges between $37.4 \%$ and $63.5 \%$, depending on the method of assessment of hydration status (urine osmolality vs. $\left.\mathrm{U}_{\mathrm{SG}}\right)^{16}$. Although the reasons for this include environmental factors such as altitude and high temperature, the lack of knowledge and understanding of the importance of euhydration by players is another determining factor. Moreover, the commonly used thirst rating is not considered a good indicator of hydration level ${ }^{15}$. A lack of proper guidance and development of a well-planned hydration schedule could also contribute to hypohydration in players ${ }^{17}$. Consider- 
ing this, proper dietary records should be maintained and urine samples should be analyzed for osmolality or specific gravity with a particular view to the players replacing daily sweat and urine losses. Finally, proper transfer of knowledge to players who seek information about sports nutrition can yield positive results, especially in the case of hydration status, as was evident for female football players ${ }^{18}$.

Given the lack of information derived from elite players regarding hydration status, the purpose of this study was (i) to assess hydration levels in elite male football players during a national team training camp before and during qualifying matches, (ii) to evaluate the effect of coaching strategies for hydration based on feedback from hydration monitoring, and (iii) to assess possible relationships between hydration status and training load or wellness markers.

\section{METHODS}

\section{Participants}

A preliminary power analysis (effect size: 0.25 , power: 0.90 , probability error: 0.05 , 2-tailed) using $G^{*}$ Power software (version 3.1.9.2, Düsseldorf University, Düsseldorf, Germany) indicated a sample size of 13 participants for a repeated-measures, within-factors design. In this study, thirty-one male European national team football players competing in a Union of European Football Associations (UEFA) tournament were recruited to participate in three camps. Table 1 shows the characteristics of the players. All playing positions were represented and players were selected for the national team during the three camps related to the UEFA Nations League in the autumn of 2020. Twenty-three players participated in camp 1, 22 players in camp 2, and 23 players in camp 3. Fourteen players were involved in all three camps. Players participated in two games during camp 1 , three games during camp 2 , and three games during camp 3 . The players were fully informed of the experimental pro-

Table 1. Player characteristics $(n=31)$.

\begin{tabular}{cccccc}
$\begin{array}{c}\text { Age } \\
\text { (yrs) }\end{array}$ & $\begin{array}{c}\text { Height } \\
(\mathbf{c m})\end{array}$ & $\begin{array}{c}\text { Weight } \\
(\mathbf{k g})\end{array}$ & $\begin{array}{c}\text { Body fat } \\
(\%)\end{array}$ & $\begin{array}{c}\text { Muscle mass } \\
(\mathbf{k g})\end{array}$ & $\begin{array}{c}\text { Yo-Yo IR2 } \\
(\mathbf{m})\end{array}$ \\
\hline $27 \pm 4$ & $185 \pm 6$ & $82.9 \pm 6.7$ & $10.4 \pm 2.3$ & $43.0 \pm 3.6$ & $1113 \pm 185$ \\
\hline
\end{tabular}

Data are mean $\pm S D$ Yo-Yo IR2: Yo-Yo intermittent recovery test level 2. cedures and possible discomfort associated with the study before giving their written informed consent. Procedures were in accordance with the 1975 Declaration of Helsinki and its later amendments, and approval was obtained from the Institutional Review Board of the University of Thessaly (protocol number 1635/02-04/2020).

\section{Design}

The design of this study is shown in Figure 1. The national team players were monitored during three consecutive camps during September (Camp 1 [C1]), October (Camp 2 [C2]), and November (Camp 3 [C3]) 2020. C1 incorporated two UEFA Nations League games separated by three days, while camps 2 and 3 incorporated three games separated by three recovery days. Descriptive characteristics of players were measured on the first day of camp 1 (MD-3). During the camps, the hydration status of players was assessed by $\mathrm{U}_{\mathrm{SG}}$. After the first measurement (baseline - MD-3 of C1), players were given a 60 -min lecture on the importance of hydration during games and training, and on optimal fluid intake strategies. After each measurement, players were given individual feedback and guidance if they showed signs of dehydration or suboptimal hydration. In addition to the training sessions, water was available during all team meetings and other events, and the players were encouraged to take in water frequently. Moreover, the wellness status and training load were recorded during the camps.

\section{Experimental Procedures}

\section{Baseline assessments}

At 8.00-9.00 am on the first day of $\mathrm{C} 1$, following an overnight fast, players' weight and body composition were measured using bioimpedance technology with an InBody 230 multi-frequency body composition analyzer (InBody 230, BioSpace, Urbandale, IA, USA), as described by Karelis et al. (2013). The participants were weighed barefoot while wearing light clothes. The data output, as calculated by an algorithm, included fat mass $(\mathrm{kg})$, body fat (\%), and lean body mass $(\mathrm{kg})$. The InBody technology has been validated with dual-energy X-ray absorptiometry (DXA) with ICCs of $0.98-0.99^{19}$. The heights of the players were measured using a portable stadiometer (Seca213; Seca GmbH,

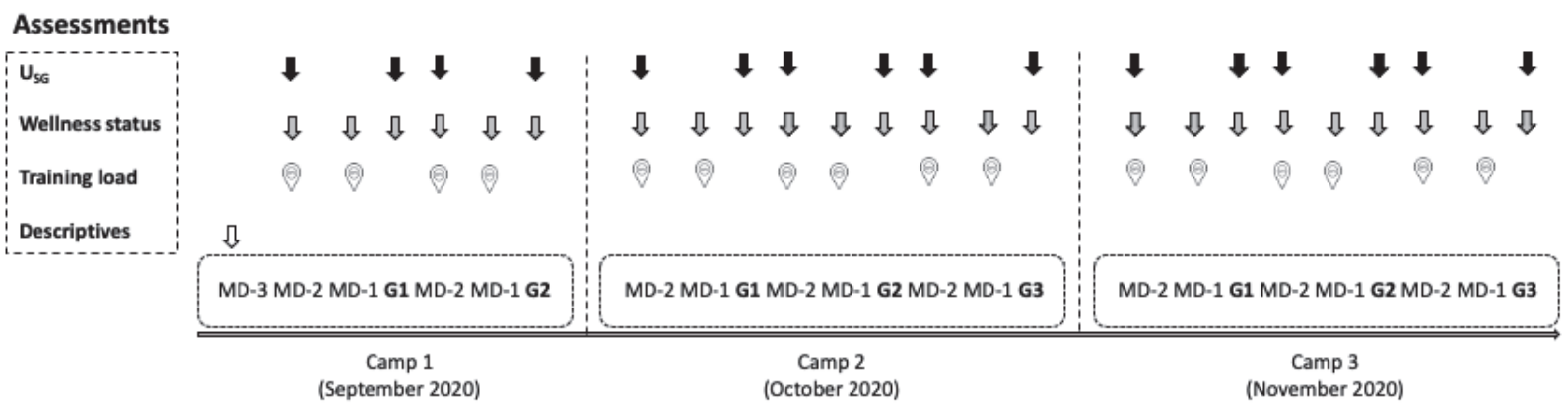

Figure 1. Study design. 
Hamburg, Germany). Fitness status was measured by YoYo IR2 testing ${ }^{20}$ during the three-four weeks prior to the camps.

\section{Urine specific gravity}

An upon-waking (8.00-9.00 am), mid-flow urine sample in a fasted and rested state was used when collecting all urine samples, as recommended ${ }^{21}$. $\mathrm{U}_{\mathrm{SG}}$ was measured in urine samples that were collected in 10-ml tubes as soon as possible after waking up and before any intake of fluid or food. The urine samples were stored at room temperature and analyzed within 30 min after sampling using a refractometer (RETK-70; Tekcoplus Ltd, Kowloon, Hong Kong). $\mathrm{U}_{\mathrm{SG}}$ was measured on day -2 (2 days before a game, MD-2) and on match-day (MD) during all three camps. During all three camps, standardized meals were consumed according to established nutritional principles in elite football ${ }^{22}$.

\section{Wellness status and training load}

Player wellness was measured using a six-section psychometric questionnaire ${ }^{23}$. The questionnaire assessed sleep duration and quality, motivation, stress levels, recovery, and muscle soreness. The previous night's sleep duration was assessed in hours, while the other four questions were scored on a 5-point scale (1 representing very, very poor, and 5 very, very good), and muscle soreness was scored on a 10 point scale $(1=$ no soreness and $10=$ very very sore $)$. Wellness questionnaires were completed immediately upon waking on days -2 and -1 and on match-days during all three camps. Activity patterns and heart rate loadings were recorded during all training sessions using Polar Pro (Polar Team Pro; Polar Electro, Kempele, Finland). External training load was evaluated by assessing the total distance covered, high-intensity running distance, sprint distance, and the number of accelerations and decelerations, as previously reported $^{12}$. The internal training load was measured using heart rate loading recordings.

\section{Educational intervention}

The lecture was in the form of a PowerPoint presentation delivered to the players in a hotel conference room. The lecture lasted $60 \mathrm{~min}$ and consisted of a $15 \mathrm{~min}$ introduction concerning the importance of proper nutrition in football; a 30 min main section concerning the importance of proper hydration for performance, the timing of fluid intake, information on good hydration practices before, during, and after training or a game, and simple ways of assessing hydration status; and a final 15 min section devoted to questions from the players. A description of the lecture is presented in Table 2. Furthermore, during all camps, the players were actively coached on improving hydration strategies and given individual feedback on their test results.

\section{Statistical analysis}

A Shapiro-Wilk test was used to test for normality of data. Differences in $\mathrm{U}_{\mathrm{SG}}$, training data, and wellness during the study period were analyzed using a one-way repeated-measures ANOVA. When a significant interaction was
Table 2. Brief description of the educational intervention.

\begin{tabular}{|c|c|}
\hline Section - Duration & Topic \\
\hline Introduction - 15 min & $\begin{array}{l}\text { Proper Nutrition in Football } \\
\text { - Every day nutrition } \\
\text { Macromolecule intake per day } \\
\text { (carbohydrates, fat, protein) } \\
\text { - Micromolecule intake } \\
\text { (vitamins, minerals) } \\
\text { - Timing of solid food and fluid } \\
\text { intake days and hours prior to } \\
\text { a game }\end{array}$ \\
\hline Main Section - 30 min & $\begin{array}{l}\text { Proper Hydration for Performance } \\
\text { - Amount of fluid intake } \\
\text { - Timing of fluid intake (before, } \\
\text { during, and after a game) } \\
\text { - Type of fluid intake } \\
\text { - Assessment of hydration } \\
\text { status } \\
\text { - Adverse effects of } \\
\text { hypohydration }\end{array}$ \\
\hline
\end{tabular}

Final Section - 15 min Questions - Answers

found, multiple comparison procedures were applied using a post-hoc least significant differences test to identify the points of difference. A dependent t-test was performed on pooled data to assess potential differences between day2 and match day. Statistical significance was set at $p \leq 0.05$. Correlations between $\mathrm{U}_{\mathrm{SG}}$ and training or wellness data were calculated using the Pearson product-moment correlation. For correlation analyses, measurements performed on MD-2 were used. Correlations between body fat percentage, which was measured in each camp, and hydrational status were also analyzed. SigmaStat software was used for all analyses (SigmaStat for Windows version 11.0). Data are presented as the mean \pm SD.

\section{RESULTS}

\section{Urine specific gravity}

The baseline $\mathrm{U}_{\mathrm{SG}}$ on the first day of the camp was $1.025 \pm 0.005$. Twenty of the 23 players $(87 \%)$ who participated in $\mathrm{C} 1$ were dehydrated (Table 3 ) at the beginning of camp, but this number progressively decreased until the end of $\mathrm{C} 1$, with only three dehydrated players $(13 \%)$ prior to game 2. The pattern was the same for $\mathrm{C} 2$, as 12 players $(55 \%)$ appeared to be dehydrated on MD-2, but this number progressively decreased to 7 dehydrated players prior to game 3. During C3, 15 players (65\%) were dehydrated on MD-2, and this number decreased to three (13\%) prior to game 3 of this camp.

Repeated measures ANOVA was performed using data from players who participated in all three camps, which revealed that $\mathrm{U}_{\mathrm{SG}}$ decreased significantly $(\mathrm{p}<0.005)$ compared to the first day of the training camps (MD-2 of C2, Table 1). Hydration status improved progressively during the three camps, with fewer dehydrated players and more well-hydrated players during the last part of $\mathrm{C} 3$ compared to the first part of $\mathrm{C} 1$. Overall, $51 \%$ of the players were dehydrated 
Table 3. Time-dependent changes in $U_{S G}(n=14)$ and hydration status.

\begin{tabular}{|c|c|c|c|c|c|c|c|c|c|c|c|c|c|c|c|c|}
\hline \multirow[b]{3}{*}{$\mathrm{U}_{\mathrm{SG}}$} & \multicolumn{4}{|c|}{ C1 } & \multicolumn{6}{|c|}{$\mathrm{C} 2$} & \multicolumn{6}{|c|}{ C3 } \\
\hline & \multicolumn{2}{|c|}{ Game-1 } & \multicolumn{2}{|c|}{ Game-2 } & \multicolumn{2}{|c|}{ Game-1 } & \multicolumn{2}{|c|}{ Game-2 } & \multicolumn{2}{|c|}{ Game-3 } & \multicolumn{2}{|c|}{ Game-1 } & \multicolumn{2}{|c|}{ Game-2 } & \multicolumn{2}{|c|}{ Game-3 } \\
\hline & MD-2 & MD & MD-2 & MD & MD-2 & MD & MD-2 & MD & MD-2 & MD & MD-2 & MD & MD-2 & MD & MD-2 & MD \\
\hline Mean & 1,024 & $1,019^{*}$ & $1,019^{*}$ & $1,014^{*}$ & $1,018^{*}$ & $1,016^{*}$ & $1,017^{*}$ & $1,015^{*}$ & $1,019^{*}$ & $1,017^{*}$ & $1,020^{*}$ & $1,016^{*}$ & $1,018^{*}$ & $1,015^{*}$ & 1,024 & $1,013^{*}$ \\
\hline SD & 0,004 & 0,004 & 0,007 & 0,003 & 0,006 & 0,003 & 0,005 & 0,004 & 0,004 & 0,005 & 0,005 & 0,004 & 0,003 & 0,003 & 0,015 & 0,005 \\
\hline $\begin{array}{l}\text { Dehydration } \\
\text { (\# of players) }\end{array}$ & 20 & 14 & 10 & 3 & 12 & 3 & 8 & 5 & 9 & 7 & 15 & 6 & 9 & 0 & 10 & 3 \\
\hline $\begin{array}{l}\text { Dehydration } \\
\text { (\% of players) }\end{array}$ & 87 & 61 & 43 & 13 & 55 & 14 & 36 & 23 & 41 & 32 & 65 & 26 & 39 & 0 & 43 & 13 \\
\hline
\end{tabular}

*Sig. vs. MD-2 of Game-1 in C1, p<0.005; C1: Camp 1; C2: Camp 2; C3: Camp 3; MD-2: Match day-2; MD: Match day; $U_{\mathrm{SG}}$ : Urine specific gravity.

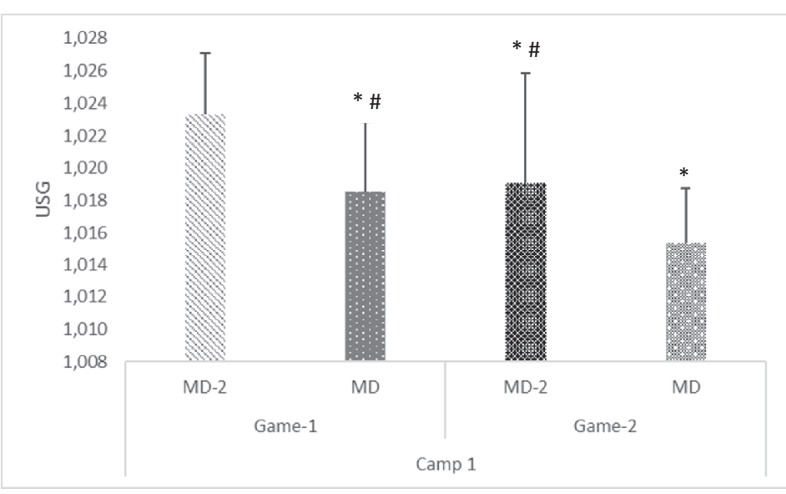

Figure 2. Changes in $\mathrm{U}_{\mathrm{SG}}$ during Camp 1.

* Sig Diff vs. MD-2, Game-1; \# Sig Diff vs. MD, Game-2; $\mathrm{U}_{\mathrm{SG}}$ : Urine specific gravity; MD-2: Match day-2; MD: Match day

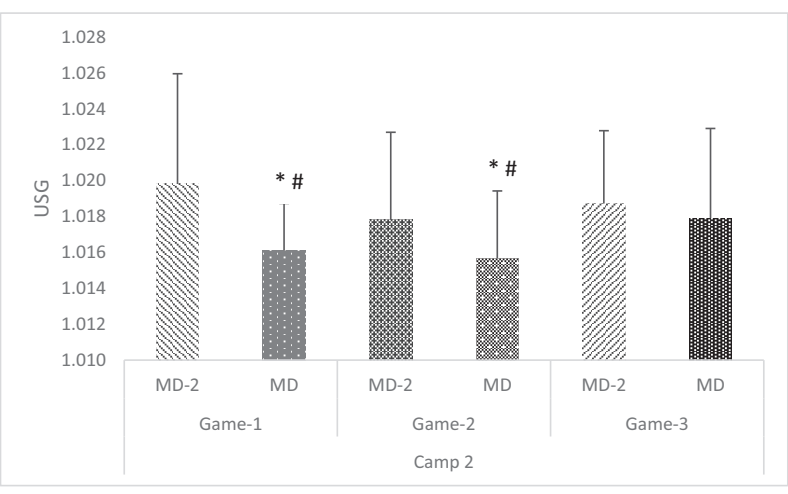

Figure 3. Changes in $\mathrm{U}_{\mathrm{SG}}$ during Camp 2

* Sig Diff vs. MD-2, Game-1; \# Sig Diff vs. MD-2, Game-3; U Urine specific gravity; MD-2: Match day-2; MD: Match day

in $\mathrm{C} 1,34 \%$ in $\mathrm{C} 2$, and $31 \%$ in $\mathrm{C} 3$.

The $\mathrm{U}_{\mathrm{SG}}$ data for each of the three camps are shown in Figures 1-3. Repeated measures ANOVA for C1 (Fig. 2) revealed that $\mathrm{U}_{\mathrm{SG}}$ was significantly lower $(\mathrm{p}<0.01)$ on the days following the first day of $\mathrm{C} 1$. Furthermore, the $\mathrm{U}_{\mathrm{SG}}$ on MD of game 2 was significantly lower $(\mathrm{p}<0.001)$ than that of game 1 and MD-2 of game 2. Data analysis of C2 (Fig. 3) revealed that $\mathrm{U}_{\mathrm{SG}}$ levels on $\mathrm{MD}$ of game 1 and game 2 were significantly $(\mathrm{p}<0.05)$ lower than those in MD-2 of games 1 and 3. Repeated measures ANOVA for the C3 data (Fig. 4) revealed that $\mathrm{U}_{\mathrm{SG}}$ levels were significantly higher compared

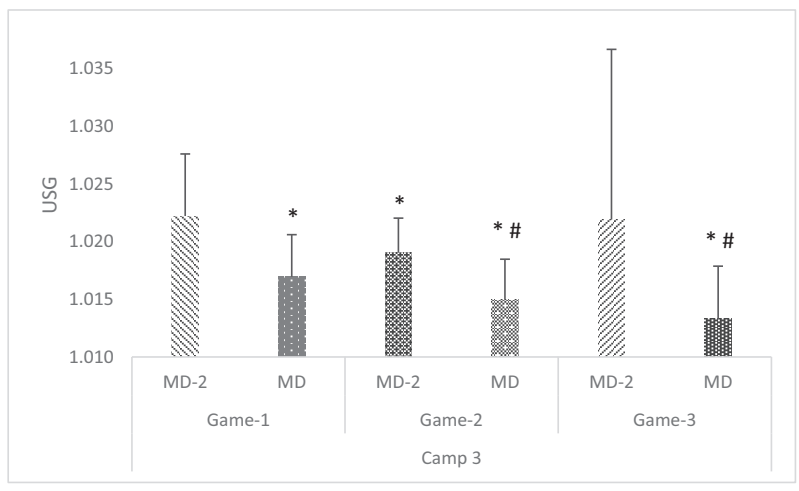

Figure 4. Changes in $\mathrm{U}_{\mathrm{sG}}$ during Camp 3.

* Sig Diff vs. MD-2, Game-1; \# Sig Diff vs. MD, Game-1 and MD-

2, Game-2; $\mathrm{U}_{\mathrm{SG}}$ : Urine specific gravity; MD-2: Match day-2; MD: Match day

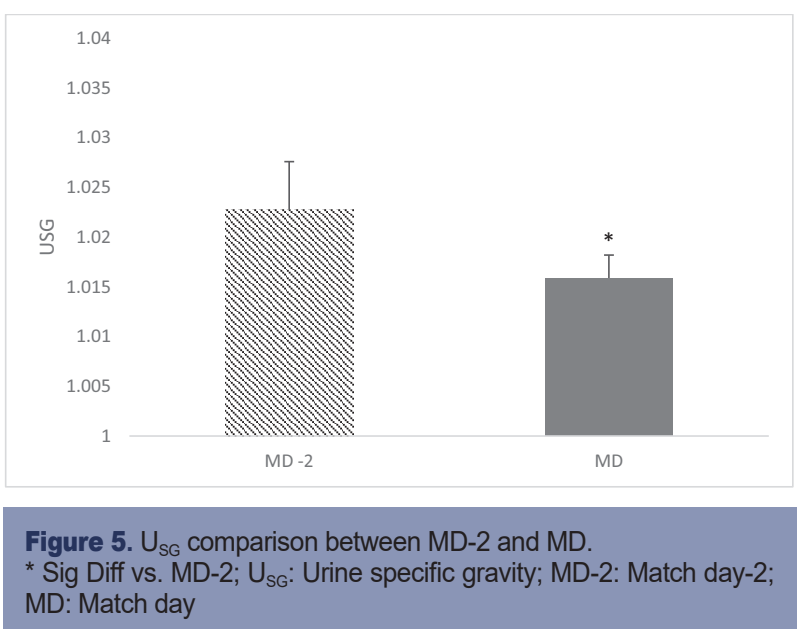

to the other points of measurement (with the exception of MD-2 of game 3). The $\mathrm{U}_{\mathrm{SG}}$ on $\mathrm{MD}$ of game 2 and game 3 was significantly $(p<0.005)$ lower than that of game 1 and day-2 of game 2 . When all the data were pooled together, $\mathrm{U}_{\mathrm{SG}}$ on MD-2 was significantly $(\mathrm{p}<0.05)$ higher than the MD values (Fig. 5). On average, $52 \%$ of the players were dehydrated on MD-2 and $6 \%$ on MD.

\section{Training load}

The total distance covered during training on MD-2 was greater $(\mathrm{P}<0.05)$ than during $\mathrm{MD}-1$, while high intensity 
running (HIR) and sprinting distance were similar on MD-2 and MD-1, except during $\mathrm{C} 1$, when HIR and sprinting distance were shorter $(\mathrm{P}<0.05)$ on MD-1 than on MD-2 (Table $3)$. Intense accelerations and decelerations occurred more frequently $(\mathrm{P}<0.05)$ on MD-2 than on MD-1. There was no difference in mean heart rate loading during training on MD-2 and MD-1 (Table 4).

\section{Wellness status}

When data from all camps were pooled together, sleep duration was shorter $(\mathrm{P}<0.05)$ the night before MD-2 compared to MD-1 and MD (Table 5), while there was no difference in sleep quality. However, sleep quality was rated higher $(\mathrm{P}<0.05)$ for the night prior to MD-1 than for MD-2 during $\mathrm{C} 2$, as well as for the night before MD-1 and MD during C3 (Table 5). The motivation score was higher $(\mathrm{P}<0.05)$ on the morning of MD than of MD-2 (Table 5). The level of stress and recovery status did not differ between days, while perceived muscle soreness was lower $(\mathrm{P}<0.05)$ on MD than on the morning of MD-2 and MD-1 (Table 5).

\section{Correlations}

No correlations were found between hydration status or body composition, training load measures, or any of the wellness indicators (Table 6).

\section{DISCUSSION}

Our study is the first to measure hydration status along with the effects of hydration monitoring and optimal coaching strategies for hydration in male national team football players during camps related to an official UEFA tournament. The principal findings were as follows: i) around 85\% of the players were classified as dehydrated on the first day of a national team camp; ii) coaching fluid intake strategies markedly improved hydration status; and iii) on average, around half of the players were dehydrated on MD-2 and only $6 \%$ on $\mathrm{MD}$.

In the present study, we classified dehydration as a $\mathrm{U}_{\mathrm{SG}}$ score of $\geq 1.020$, as previously suggested ${ }^{21,24}$. Based on this definition, the majority of the players were dehydrated, and none were euhydrated $\left(\mathrm{U}_{\mathrm{SG}} \leq 1.015\right)$ on the first day of the national team camps. Thus, it appears that elite football players may generally suffer from hypohydration prior to participation in a training camp. Hypohydration has a significant negative effect on both physiological and cognitive performance, as well as technical skills ${ }^{15}$. Four out of the

Table 4. Training load measures during the three national team camps.

\begin{tabular}{|c|c|c|c|c|c|c|}
\hline & \multicolumn{2}{|c|}{ C1 } & \multicolumn{2}{|c|}{ C2 } & \multicolumn{2}{|c|}{ C3 } \\
\hline & MD-2 & MD-1 & MD-2 & MD-1 & MD-2 & MD-1 \\
\hline Total Distance (m) & $5567 \pm 942$ & $4107 \pm 444^{*}$ & $5597 \pm 822$ & $4758 \pm 590^{*}$ & $5401 \pm 956$ & $4540 \pm 75^{*}$ \\
\hline High-intensity running (m) & $719 \pm 202$ & $456 \pm 177^{*}$ & $713 \pm 233$ & $704 \pm 215$ & $768 \pm 359$ & $803 \pm 312$ \\
\hline Sprint distance $(\mathrm{m})$ & $102 \pm 72$ & $53 \pm 44^{*}$ & $99 \pm 55$ & $108 \pm 59$ & $99 \pm 85$ & $148 \pm 99$ \\
\hline Intense accelerations ( $\mathrm{n}$ ) & $80 \pm 14$ & $50 \pm 11^{*}$ & $82 \pm 12$ & $52 \pm 11^{*}$ & $88 \pm 12$ & $54 \pm 14^{*}$ \\
\hline Intense decelerations ( $\mathrm{n}$ ) & $70 \pm 15$ & $43 \pm 11^{*}$ & $72 \pm 16$ & $51 \pm 12^{*}$ & $77 \pm 22$ & $54 \pm 1 * 3$ \\
\hline Mean HR (\% HRmax) & $78.3 \pm 3.3$ & $77.2 \pm 3.9$ & $77.9 \pm 3.6$ & $76.8 \pm 3.2$ & $79.4 \pm 3.7$ & $77.8 \pm 3.6$ \\
\hline
\end{tabular}

${ }^{*}$ Sig. vs. Day -2, p<0.05; Data are presented as mean \pm SD. HR: Heart rate; C1: Camp 1; C2: Camp 2; C3: Camp 3; MD-2: Match day-2; MD-1: Match day-1.

Table 5. Wellness measures during the three national team camps.

\begin{tabular}{ccccccccccc} 
& \multicolumn{3}{c}{ C1 } & \multicolumn{3}{c}{ C2 } & & \\
& & MD-2 & MD-1 & MD & MD-2 & MD-1 & MD & MD-2 & MD-1 & MD \\
\cline { 2 - 8 } Sleep duration (h) & $6.8 \pm 1.3$ & $7.6 \pm 0.8$ & $7.8 \pm 0.8$ & $6.7 \pm 1.4$ & $7.9 \pm 0.8$ & $6.9 \pm 1.0$ & $6.9 \pm 1.2$ & $7.6 \pm 0.7$ & $7.9 \pm 0.8$ \\
\hline Sleep quality (au) & $4.0 \pm 0.8$ & $3.9 \pm 0.6$ & $3.8 \pm 0.6$ & $3.3 \pm 0.9$ & $3.7 \pm 0.6^{*}$ & $3.4 \pm 0.9$ & $3.2 \pm 0.9$ & $3.7 \pm 0.8^{*}$ & $3.9 \pm 0.7$ \\
Motivation (au) & $4.0 \pm 1.0$ & $4.0 \pm 0.8$ & $4.6+0.8^{*}$ & $3.8+0.8$ & $4.2 \pm 0.8$ & $4.0 \pm 0.7^{*}$ & $3.9 \pm 1.0$ & $4.0 \pm 0.6$ & $4.4 \pm 0.5^{*}$ \\
\hline Stress (au) & $3.7 \pm 0.9$ & $3.6 \pm 0.8$ & $3.4 \pm 0.8$ & $3.8 \pm 0.7$ & $3.7 \pm 0.7$ & $3.6 \pm 0.8$ & $3.8 \pm 0.8$ & $3.7 \pm 0.6$ & $3.6 \pm 0.7$ \\
Recovery (au) & $2.9 \pm 0.8$ & $2.9 \pm 0.6$ & $3.2 \pm 0.7$ & $2.8 \pm 0.6$ & $3.4 \pm 0.6$ & $2.7 \pm 0.6$ & $2.8 \pm 0.8$ & $3.2 \pm 0.5$ & $2.8 \pm 0.6$ \\
Muscle soreness (au) & $6.0 \pm 1.5$ & $6.3 \pm 1.2$ & $5.6+1.3^{\#}$ & $5.6 \pm 1.3$ & $5.9 \pm 1.5$ & $5.3 \pm 1.9^{\#}$ & $5.4 \pm 2.0$ & $5.7 \pm 1.4$ & $5.2 \pm 1.5^{\#}$ \\
\hline
\end{tabular}

Sleep quality, and levels of motivation, stress, and recovery status are expressed on a 1-5-point scale and muscle soreness on a 1-10-point scale.

${ }^{*}$ Sig. vs. Day -2, p<0.05; "Sig. vs. Day -2 and Day -1; p<0.05; Data are mean \pm SD of MD-2, MD-1, and MD during each camp. C1: Camp 1; C2: Camp 2; C3: Camp 3; MD-2: Match day-2; MD-1: Match day-1; MD: Match day.

Table 6. Correlations between hydration status and training load variables, body composition, and wellness markers.

$\begin{array}{cc}\text { Variable } & \text { Hydrational status } \\ \text { Total distance covered MD-2 and } U_{S G} & r^{2}=0.04 ; p>0.05(n=158) \\ \text { High intensity running MD -2 and } U_{S G} & r^{2}=0.06 ; p>0.05(n=158) \\ \% H R_{\text {max }} \text { MD-2 and } U_{S G} & r^{2}=0.07 ; p>0.05(n=158) \\ \text { Body fat percentage and } U_{S G} & r^{2}=0.03 ; p>0.05(n=168) \\ \text { Wellness markers and } U_{S G} & r^{2}=0.03-0,08 ; \text { all } p>0.05(n=158)\end{array}$

Inter-individual relationships between hydrational status and indicators of training load, body composition, and wellness. MD-2: Match day-2; $\mathrm{U}_{\mathrm{SG}}$ : Urine specific gravity; $\mathrm{HR}_{\text {max }}$ : Maximum heart rate. 
five players in this study were rated as hypohydrated during the training camp. Previous reports have indicated a lower rate of hypohydration in football players ${ }^{13,15}$. It is well established that thirst does not constitute a proper measure for dictating fluid intake, and proper hydration guidance should be provided to players to prevent hypohydration and induce proper hydration levels ${ }^{15,25}$. The results of this study support this suggestion, since the educational intervention that was implemented in order to advise for proper hydration resulted in progressively lower dehydration rates in players participating in this series of football fixtures. Consequently, in order to avoid performance decline and impairments in cognitive function and technical skill, it is necessary to make a continuous effort to educate players on the advantages of proper hydration. In addition, frequent monitoring and individual feedback from players are needed if euhydration is the main goal.

Hypohydration has been correlated with lower physical performance at the meta-analysis level ${ }^{26}$ and during football match-play ${ }^{12}$. The results of this study are not in line with those in the literature because we did not find any relationship between improvements in hydration status and increments in exercise performance in the training days preceding matches during the three tournament camps. It should be noted, however, that this was an observational study, and the research design was such that we followed the training schedule of the team without intervening in the training load. Since the periodization prior to each game was such that the training load was lowered leading up to a game, it is difficult to draw firm conclusions about the impact of hydration status on exercise performance; therefore, the research design is acknowledged as a limitation of this study. A control condition or the inclusion of a control group not undergoing educational intervention would provide more firm conclusions.

Previous research indicates that educational interventions that highlight the importance of proper hydration practices might have short-term benefits ${ }^{27}$. However, this has not been studied thoroughly in elite football players, and future research should examine whether a continuous effort to implement an educational program relating to proper hydration strategies can result in positive effects on hydration status.

Wellness questionnaires have been used recently in an effort to decipher the stress levels of football players ${ }^{23}$. Gathering such data can help the support team (coaches, trainers, physiotherapists, doctors, etc.) of the players to manage stress levels from a physiological and psychological standpoint. Previous research has shown that the training load can be monitored successfully using wellness questionnaires ${ }^{23}$. In our study, there was no correlation between the wellness and performance-related variables. Thorpe et al. (2015) also reported a non-significant relationship between muscle soreness and sleep quality related to acute daily fluctuations in the training load. Sleep quality and sleep duration are important factors that contribute to injuries in football players ${ }^{28}$. Silva et al. have shown that sleep efficiency could explain $44 \%$ of the total variance in the number of injuries, $24 \%$ of the total variance in absence time after injury (days), and $47 \%$ of the total variance in injury severity $^{29}$. Furthermore, data indicate that sports requiring a high level of speed and technical skills, such as football, are more sensitive to sleep manipulation ${ }^{30}$. In our study, sleep duration ranged between 7-8 h, and there were no statistically significant differences between training camps and days leading up to a game. Furthermore, there was no association between performance, sleep quality, and sleep duration.

The present study was designed as an observational case study in which a Scandinavian National team was monitored in a controlled setting during an official camp. The participants were professional players in various Northern European leagues. Thus, a limitation is that the findings may differ in other cultural settings. We applied urine specific gravity as a marker of hydration status, which is commonly used and shows good validity ${ }^{31}$. Confounding factors in relation to the application of $\mathrm{U}_{\mathrm{SG}}$ to assess dehydration may be associated with factors such as sampling time, pathological conditions, high muscle mass, excess protein intake, and frequent engagement in high-intensity training ${ }^{21}$. In the present study, all samples were obtained according to standard procedures upon waking in the morning, and the participants were professional athletes without chronic disease. Moreover, the participants did not have extreme muscle mass, which could result in proteinuria, and no correlation was found between muscle mass and $\mathrm{U}_{\mathrm{SG}}$. Altered renal blood flow and proteinuria have also been linked to engagement in frequent high-intensity training ${ }^{21}$. However, training during the camp was at moderate intensity, and no systematic difference in hydration status was observed between regular players and substitutes, which speaks against these effects. Finally, the players consumed a high-carbohydrate diet during the camp, and no additional protein was provided. Collectively, these considerations indicate a minor confounding effect on the urine assessments.

In conclusion, hypohydration appears to be a challenge in elite male football, but continuous monitoring of hydration status and coaching of hydration strategies using individual feedback induces a major improvement and reduces the degree of dehydration. Hydration status does not appear to be associated with body composition, training load, or wellness status during a training camp.

\section{REFERENCES}

1. Mohr M, laia F. Physiological basis of fatigue resistance training in competitive football. Sports Science Exchange. 2014;27:1-9.

2. Collins J, Maughan RJ, Gleeson M, Bilsborough J, Jeukendrup A, Morton JP, Phillips SM, Armstrong L, Burke LM, Close GL, Duffield R, Larson-Meyer E, Louis J, Medina D, Meyer F, Rollo I, Sundgot-Borgen J, Wall BT, Boullosa B, Dupont G, Lizarraga A, Res P, Bizzini M, Castagna C, Cowie CM, D'Hooghe M, Geyer H, Meyer T, Papadimitriou N, Vouillamoz M, McCall A. UEFA expert group statement on nutrition in elite football. current evidence to inform practical recommendations and guide future research. $\mathrm{Br} J$ Sports Med. 2021;55:416.

3. Al-Jaser TA, Hasan AA. Fluid loss and body composition of elite 
Kuwaiti soccer players during a soccer match. J Sports Med Phys Fitness. 2006;46:281-5.

4. Duffield R, McCall A, Coutts AJ, Peiffer JJ. Hydration, sweat and thermoregulatory responses to professional football training in the heat. J Sports Sci. 2012;30:957-65.

5. Maughan RJ, Shirreffs SM, Merson SJ, Horswill CA. Fluid and electrolyte balance in elite male football (soccer) players training in a cool environment. J Sports Sci. 2005;23:73-9.

6. Shirreffs SM, Aragon-Vargas LF, Chamorro M, Maughan RJ, Serratosa L, Zachwieja JJ. The sweating response of elite professional soccer players to training in the heat. Int J Sports Med. 2005;26:90-5

7. González-Alonso J, Mora-Rodríguez R, Below PR, Coyle EF. Dehydration reduces cardiac output and increases systemic and cutaneous vascular resistance during exercise. J Appl Physiol (1985). 1995; 79:1487-96.

8. Kenefick RW, Cheuvront SN. Hydration for recreational sport and physical activity. Nutr Rev. 2012;2:137-42.

9. Ganio MS, Armstrong LE, Casa DJ, McDermott BP, Lee EC, Yamamoto LM, Marzano S, Lopez RM, Jimenez L, Le Bellego L, Chevillotte $E$, Lieberman HR. Mild dehydration impairs cognitive performance and mood of men. Br J Nutr. 2011;106:1535-43.

10. Mohr M, Krustrup P. Heat stress impairs repeated jump ability after competitive elite soccer games. J Strength Cond Res. 2013;27:683-9.

11. McGregor SJ, Nicholas CW, Lakomy HK, Williams C. The influence of intermittent high-intensity shuttle running and fluid ingestion on the performance of a soccer skill. J Sports Sci. 1999;17:895-903.

12. Mohr M, Nybo L, Grantham J, Racinais S. Physiological responses and physical performance during football in the heat. PLOS One. 2012;7:e39202.

13. Ali A, Gardiner R, Foskett A, Gant N. Fluid balance, thermoregulation and sprint and passing skill performance in female soccer players. Scand J Med Sci Sports. 2011;21:437-45.

14. Ali A, Williams $\mathrm{C}$. Isokinetic and isometric muscle function of the knee extensors and flexors during simulated soccer activity: effect of exercise and dehydration. J Sports Sci. 2013;31:907-16.

15. Nuccio RP, Barnes KA, Carter JM, Baker LB. Fluid balance in team sport athletes and the effect of hypohydration on cognitive, technical, and physical performance. Sports Med. 2017;47:1951. 82.

16. Chapelle L, Tassignon B, Rommers N, Mertens E, Mullie P, Clarys P. Pre-exercise hypohydration prevalence in soccer players: a quantitative systematic review. Eur J Sport Sci. 2020;20:744-55.

17. McDermott BP, Anderson SA, Armstrong LE, Casa DJ, Cheuvront SN, Cooper L, Kenney WL, O'Connor FG, Roberts WO. National athletic trainers' association position statement: fluid replacement for the physically active. J Athl Train. 2017;52:877-95.

18. Mattausch NR, Domnik K, Koehler K, Schaenzer W, Braun H. Case study: hydration intervention improves pre-game hydration status in female collegiate soccer players. Int J Sport Nutr Exerc Metab. 2017;27:475-81.

19. Karelis AD, Chamberland G, Aubertin-Leheudre M, Duval C. Validation of a portable bioelectrical impedance analyzer for the assessment of body composition. Appl Physiol Nutr Metab. 2013:38:27-32.

20. Krustrup P, Mohr M, Nybo L, Jensen JM, Nielsen JJ, Bangsbo J.
The Yo-Yo IR2 test: physiological response, reliability, and application to elite soccer. Med Sci Sports Exerc. 2006;38:1666-73.

21. Zubac D, Reale R, Karnincic H, Sivric A, Jelaska I. Urine specific gravity as an indicator of dehydration in Olympic combat sport athletes; considerations for research and practice. Eur J Sport Sci. 2018:18:920-9.

22. Needleman I, Rankin A, Ashley P, Fairbrother T, Fine P, Gallagher J, Kings D, Maughan RJ, Melin AK, Naylor M. Infographic. nutrition and oral health in sport: time for action. $\mathrm{Br} J$ Sports Med. 2019;53:1432-3.

23. Thorpe RT, Strudwick AJ, Buchheit M, Atkinson G, Drust B, Gregson $\mathrm{W}$. Tracking morning fatigue status across in-season training weeks in elite soccer players. Int J Sports Physiol Perform. 2016;11:947-52.

24. Sawka MN, Burke LM, Eichner ER, Maughan RJ, Montain SJ, Stachenfeld NS. American college of sports medicine position stand. exercise and fluid replacement. Med Sci Sports Exerc. 2007:39:377-90.

25. Martín-Payo R, Fernández-Álvarez MDM, Zabaleta-Del-Olmo E, García-García R, González-Méndez X, Carrasco-Santos S. Feasibility study of an educational intervention to improve water intake in adolescent soccer players: a two-arm, non-randomized controlled cluster trial. Int J Environ Res Public Health. 2021;18.

26. Goulet ED. Effect of exercise-induced dehydration on time-trial exercise performance: a meta-analysis. $\mathrm{Br} J$ Sports Med. 2011;45:1149-56.

27. Atkins WC, McDermott BP, Kanemura K, Adams JD, Kavouras SA. Effects of hydration educational intervention in high school football players. J Strength Cond Res. 2021;35:385-90.

28. Thorpe RT, Strudwick AJ, Buchheit M, Atkinson G, Drust B, Gregson W. Monitoring fatigue during the in-season competitive phase in elite soccer players. Int J Sports Physiol Perform. 2015;10:95864.

29. Silva A, Narciso FV, Soalheiro I, Viegas F, Freitas LSN, Lima A, Leite BA, Aleixo HC, Duffield R, de Mello MT. Poor sleep quality's association with soccer injuries: preliminary data. Int J Sports Physiol Perform. 2020;15:671-6.

30. Kirschen GW, Jones JJ, Hale L. The impact of sleep duration on performance among competitive athletes: a systematic literature review. Clin J Sport Med. 2020;30:503-12.

31. Stuempfle KJ, Drury DG. Comparison of 3 methods to assess urine specific gravity in collegiate wrestlers. J Athl Train. 2003;38:315-9 